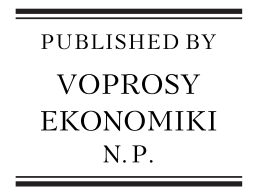

Russian Journal of Economics 7 (2021) 200-212

DOI 10.32609/j.ruje.7.65328

Publication date: 3 December 2021

Russian

Journal of

Economics

\title{
COVID-19 impacts on financial markets: Takeaways from the third wave
}

\author{
Hamza Bouhali ${ }^{\mathrm{a}, *}$, Ahmed Dahbani $^{\mathrm{b}}$, Brahim Dinar ${ }^{\mathrm{b}}$ \\ ${ }^{a}$ Mohammadia School of Engineering, Rabat, Morocco \\ ${ }^{\mathrm{b}}$ Hassan 1st University, Settat, Morocco
}

\begin{abstract}
This study provides an updated analysis of the impact of COVID-19 daily contaminations and vaccinations on the financial markets by incorporating the third wave observed in 2021. Our methodology is based on a comparative approach using a multivariate heteroscedasticity model and data from the Eurozone and ten other countries from different economies. Our results show that COVID-19 contaminations and vaccinations strongly affected most of the countries in our sample (except for the UK, Russia and India in the case of COVID-19 contaminations). We also found that optimistic market sentiment concerning the evolution of the pandemic prevailed among the countries forming our sample (except for Switzerland, Russia and India).
\end{abstract}

Keywords: COVID-19, exchange rates, vaccine, financial market.

JEL classification: F31, G15, E52.

\section{Introduction}

Following the initial outbreak in Wuhan in December 2019, the spectacular scale and spread of the deadly coronavirus forced authorities worldwide to implement rounds of economically damaging lockdowns and to put global supply chains in a standstill mode. The high socio-economic costs associated with COVID-19 contaminations triggered extreme risk aversion globally, causing a sharp liquidity squeeze across the financial markets and massively dumping many asset class valuations. If the panic reaction of the global financial markets was primarily expected due to the high uncertainty surrounding this economic shock, the extent of the collapse, however, was unparalleled, as illustrated by the meltdown of the major stock markets' indices worldwide.

\footnotetext{
* Corresponding author, E-mail address: hamzaelbouhali@gmail.com
} 
The bond, credit, and commodities markets' behaviors reflected the general pessimistic mood, with the government bonds' long term yields plunging to historic record lows due to the prolonged depression and significant investors' concerns despite the disproportionate scale of public debt monetization and exponential growth of major central banks' balance sheets (Zhanga et al., 2020).

Unsurprisingly, emerging and frontier financial markets suffered more disruptions in comparison with the developed markets owing to the gap of market maturity and their high exposition to the sectors which were hard hit by the pandemic (Topcu and Gulal, 2020; Gherghina et al., 2020; Hofmann et al., 2021). Meanwhile, the fiscal and monetary contingency plans in the United States and Western Europe aiming to reduce the pandemic's economic and social fallouts resulted in a striking disconnection between financial markets' performance and the state of the real economy in many countries. For example, we observed a spectacular rise in stocks market capitalization in the U.S. while the country's major macroeconomic indicators were struggling in negative territory (Baker et al., 2020).

Against this background, many researchers started analyzing the financial market's behavior shift during the pandemic. The first line of research adopted a comparative approach using econometric modeling to exhibit the change in the financial market's behavior after the breakout of the COVID-19 pandemic by splitting their sample into pre-pandemic and post-pandemic periods. We cite various articles such as Adenomon et al. (2020) for Nigerian Stock Exchange Market, Gherghina et al. (2021) for the Romanian Stock Market, Narayan (2020) for the Japanese exchange rate market and Salisu et al. (2020) for the commodities Market (oil and gold). The second type of research focused more precisely on the relationship between COVID-19 daily contaminations and took into account the financial assets' performance. We could mention papers such as Hoshikawa and Yoshimi (2021) for the Korean exchange rate and stock markets, Ozturk and Cavdar (2021) for both the Turkey exchange rate market and global oil, gold and bitcoin markets and Shaikh and Huynh (2021) for options on both forex and stock markets in the U.S. The last line of research concentrated on the impact of daily vaccination numbers on financial markets' standing. We make special mention of the studies of Rouatbi et al. (2021) for a 66 countries' sample and Yiu and Tsang (2021) for the ASEAN stock markets, as well as the work of Khalfaoui et al. (2021) for the S\&P 500 (U.S.).

Although research on the impact of the COVID-19 pandemic on financial assets' behavior is exhaustive, most of the studies reported in the previous paragraph focused on the daily contaminations in a single case country or on an economic coalition. Our study aims to provide an updated analysis of the impact of COVID-19 daily contaminations and vaccinations on the financial markets by incorporating the third wave observed in 2021 . We will adopt a synthetic approach inspired by the work of Hai Le et al. (2020), Iyke (2020), Feng et al. (2021) ans Rouatbi et al. (2021) with four significant differences. First, the models used so far in the literature for this subject are the univariate GARCH model (Benzid and Chebbi, 2020; Gherghina et al., 2021; Ozturk and Cavdar, 2021), different types of regressions (Kartal et al., 2021; Rouatbi et al., 2021; Hoshikawa and Yoshimi, 2021). In our study, we will use the DCC GARCH model introduced by Engle (2002). The choice of this model, commonly 
employed in the economic literature to study financial time series, will allow us to gauge the level of dynamic correlation between the chosen time series efficiently through time. The second difference will consist of using a sample incorporating the main countries from both developed and emerging markets to exhibit the impact of market maturity. The third difference will entail the dual use of daily COVID-19 contaminations and vaccinations' numbers to investigate their effect on the forex market during the pandemic. We will also use these results to assess market sentiment prevailing in the studied financial markets (hope vs. fear effect). A few articles such as Salisu and Akanni (2020), Selmi and Bouoiyour (2020), Guindy (2021), and Ngo and Nguyen (2021) discussed the subject using a combination of COVID-19 contaminations and deaths data but vaccinations data was never incorporated. Finally, we focused on the foreign exchange market rather than other assets due to its status as the world's biggest financial market (Tunç, 2004). It's also a market characterized by high efficiency (Shmilovici et al., 2008) and significant liquidity compared to other financial assets (Makovský, 2014), making it a perfect proxy to exhibit the impacts of COVID-19 contaminations.

The significant findings of our study are that COVID-19 contaminations strongly impacted the majority of studied countries from developed and emerging markets (except the UK and South Korea), with an even more substantial impact in the cases of Russia and India. We also found that COVID-19 vaccinations strongly impacted all the studied countries, especially those composing the Euro bloc. Finally, our results showed that most of the studied countries had an optimistic market sentiment concerning the evolution of the pandemic and its impact on the financial market except for Switzerland, Russia and India.

The article will be organized as follows: in section 2, we present the sample data, we then expose the methods used in our study in section 3 . We give the empirical findings of this research in section 4 and the concluding remarks in section 5 .

\section{Data and methodology}

\subsection{Data presentation}

The staggering health and socio-economic tolls of COVID-19 hit every corner of the globe, but the impact varied across countries depending on their specific economic and financial structures. Therefore, setting up an appropriate sample of nations was one of the main challenges for our study. We selected ten countries representing significant types of world economies. We also incorporated the Eurozone as a whole bloc to ensure a more coherent analysis of the euro exchange rate behavior. Furthermore, we converted all the daily closing exchange rates to be expressed in indirect quotations against the U.S. dollar. ${ }^{1}$

To properly investigate the United States case, we will use the CBOE (Chicago Board of Trade) Volatility Index (VIX), commonly known on the financial markets as the fear index. We will also explore the dynamic correlation between

1 Under this method, the foreign exchange rate of a U.S. dollar is expressed as number of units of each country currency: USD $1=$ EUR 0.87 as an example 
the gold price against the U.S. dollar, considered a safe haven by investors, and the new daily contaminations and vaccinations worldwide. The selected countries, the chosen currency pairs, and the data sample for each country are listed in Tables 1 and 2. The used data is plotted in logarithms in Figs. 1, 2, and 3.

The closing exchange rates were obtained from the central banks' websites for the different countries, the daily data of the VIX index from the CBOE website, the daily COVID-19 new contaminations, and the vaccination data from the World Health Organisation (WHO) website.

Table 1

Countries, currency pairs, and selected time frame for the study of new contaminations' impact on forex market volatility.

\begin{tabular}{llc}
\hline Country & F.X. pair & $\begin{array}{c}\text { Time frame (based on } \\
\text { the first declared case) }\end{array}$ \\
\hline $\begin{array}{l}\text { Developed markets } \\
\text { United States }\end{array}$ & VIX & $01 / 21 / 2020-06 / 30 / 2021$ \\
$\quad$ Eurozone & USD/EUR & $01 / 25 / 2020-06 / 30 / 2021$ \\
Switzerland & USD/CHF & $02 / 26 / 2020-06 / 30 / 2021$ \\
United Kingdom & USD/GBP & $02 / 01 / 2020-06 / 30 / 2021$ \\
South Korea & USD/KRW & $01 / 20 / 2020-06 / 30 / 2021$ \\
Japan & USD/JPY & $01 / 15 / 2020-06 / 30 / 2021$ \\
& & \\
Emerging markets & USD/RUB & \\
$\quad$ Russia & USD/ZAR & $02 / 01 / 2020-06 / 30 / 2021$ \\
South Africa & USD/INR & $03 / 06 / 2020-06 / 30 / 2021$ \\
India & USD/CNY & $01 / 30 / 2020-06 / 30 / 2021$ \\
China & USD/TRY & $12 / 31 / 2019-06 / 30 / 2021$ \\
Turkey & GOLD price against USD & $03 / 12 / 2020-06 / 30 / 2021$ \\
Worldwide & & $12 / 31 / 2019-06 / 30 / 2021$ \\
\hline
\end{tabular}

Source: Compiled by the authors.

Table 2

Countries, currency pairs, and selected time frame for the study of the impact of vaccinations on forex market volatility.

\begin{tabular}{llc}
\hline \multicolumn{1}{c}{ Country } & F.X.pair & $\begin{array}{l}\text { Time frame (based on } \\
\text { the first vaccine shot given) }\end{array}$ \\
\hline $\begin{array}{l}\text { Developed markets } \\
\text { United States }\end{array}$ & VIX & $12 / 21 / 2020-06 / 30 / 2021$ \\
$\quad$ Eurozone & USD/EUR & $12 / 21 / 2020-06 / 30 / 2021$ \\
Switzerland & USD/CHF & $12 / 23 / 2020-06 / 30 / 2021$ \\
United Kingdom & USD/GBP & $12 / 14 / 2020-06 / 30 / 2021$ \\
South Korea & USD/KRW & $03 / 01 / 2021-06 / 30 / 2021$ \\
Japan & USD/JPY & $02 / 18 / 2021-06 / 30 / 2021$ \\
& & \\
Emerging markets & & \\
Russia & USD/RUB & $12 / 16 / 2020-06 / 30 / 2021$ \\
South Africa & USD/ZAR & $12 / 17 / 2020-06 / 30 / 2021$ \\
India & USD/INR & $01 / 19 / 2021-06 / 30 / 2021$ \\
China & USD/CNY & $12 / 16 / 2020-06 / 30 / 2021$ \\
Turkey & USD/TRY & $01 / 14 / 2021-06 / 30 / 2021$ \\
Worldwide & GOLD price against USD & $12 / 14 / 2020-06 / 30 / 2021$ \\
\hline
\end{tabular}

Source: Compiled by the authors. 

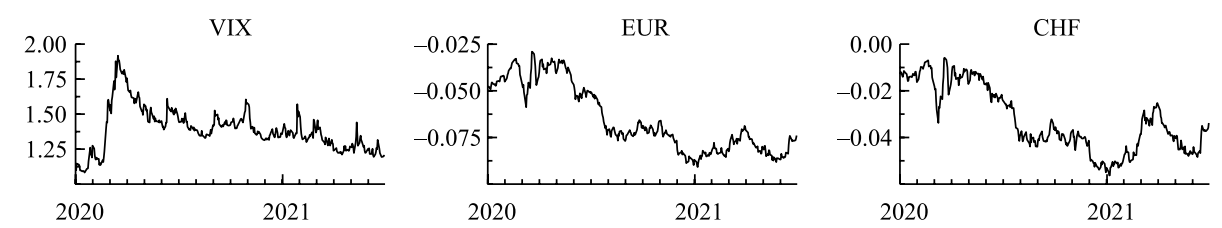

GBP

KRW
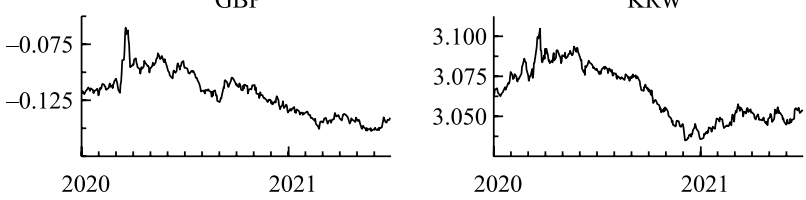

JPY
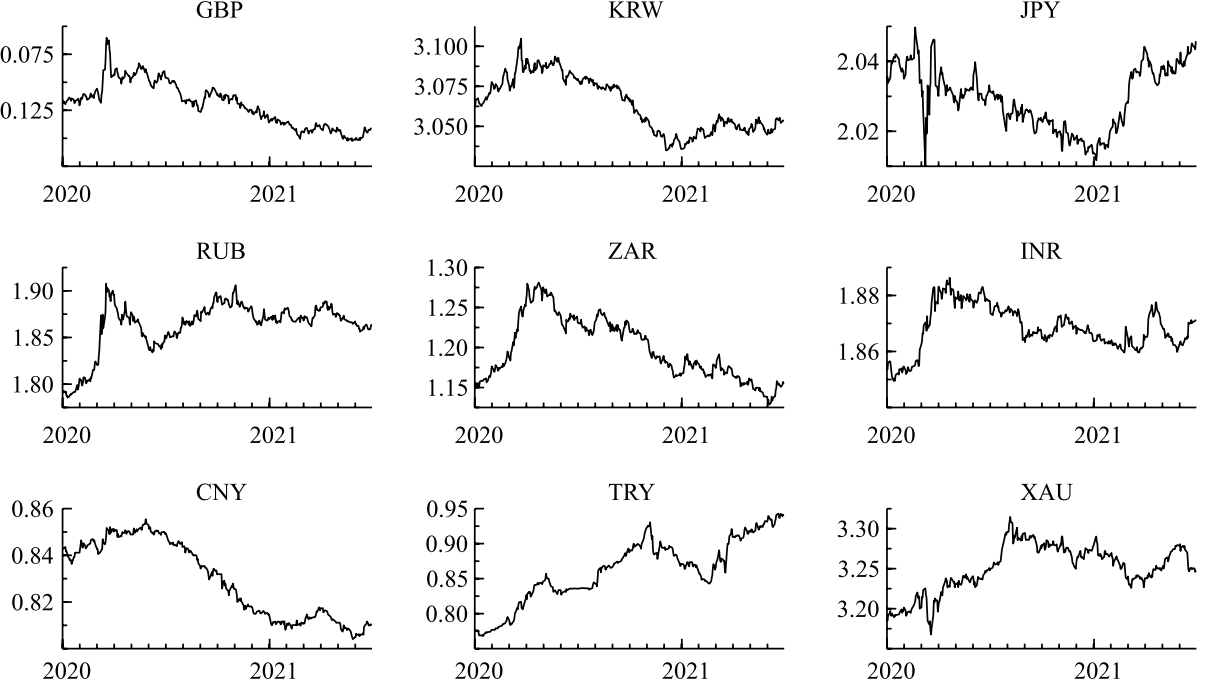

Fig. 1. Daily logarithmic closing rates against the U.S. dollars for the studied series. Source: Authors' calculations.
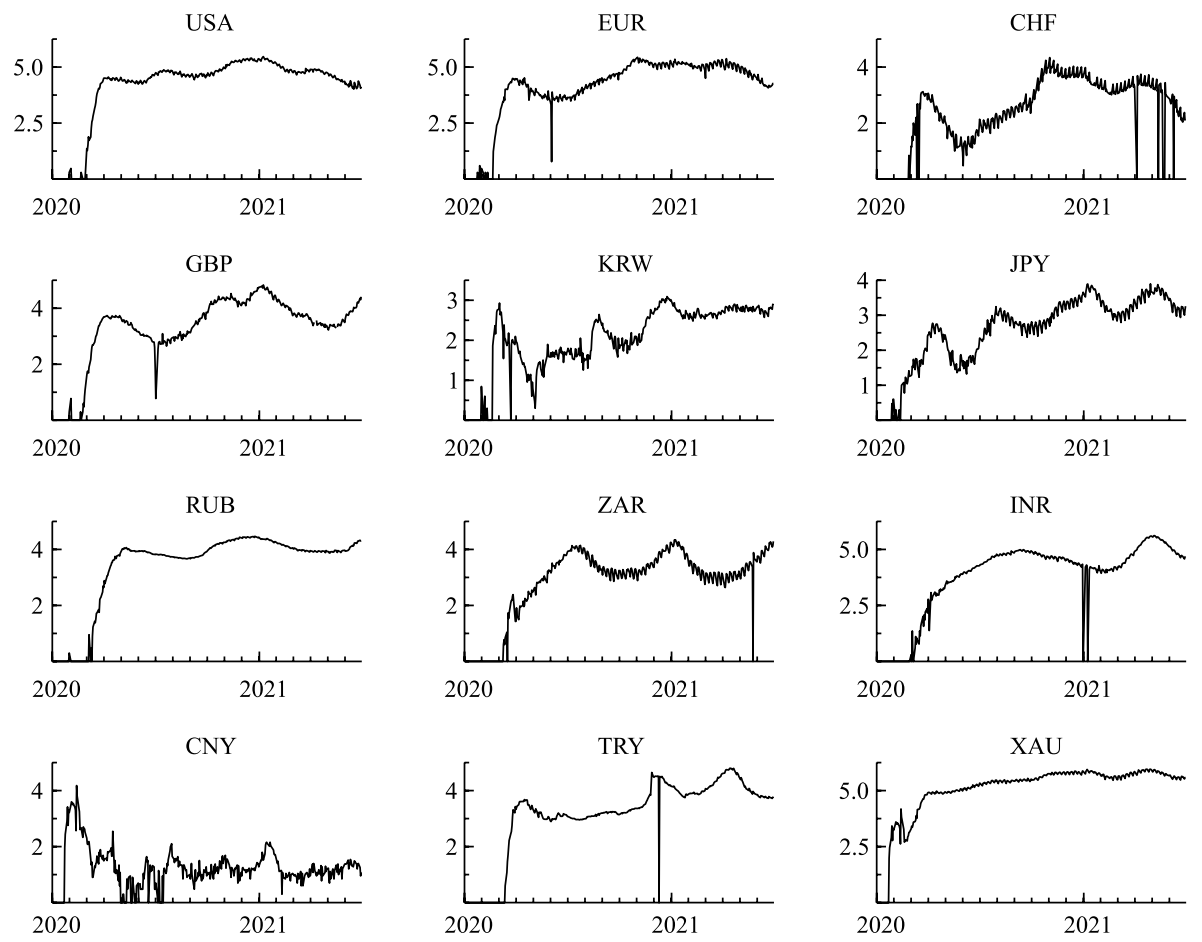

Fig. 2. Daily logarithmic new COVID-19 contamination for the studied countries.

Source: Authors' calculations. 

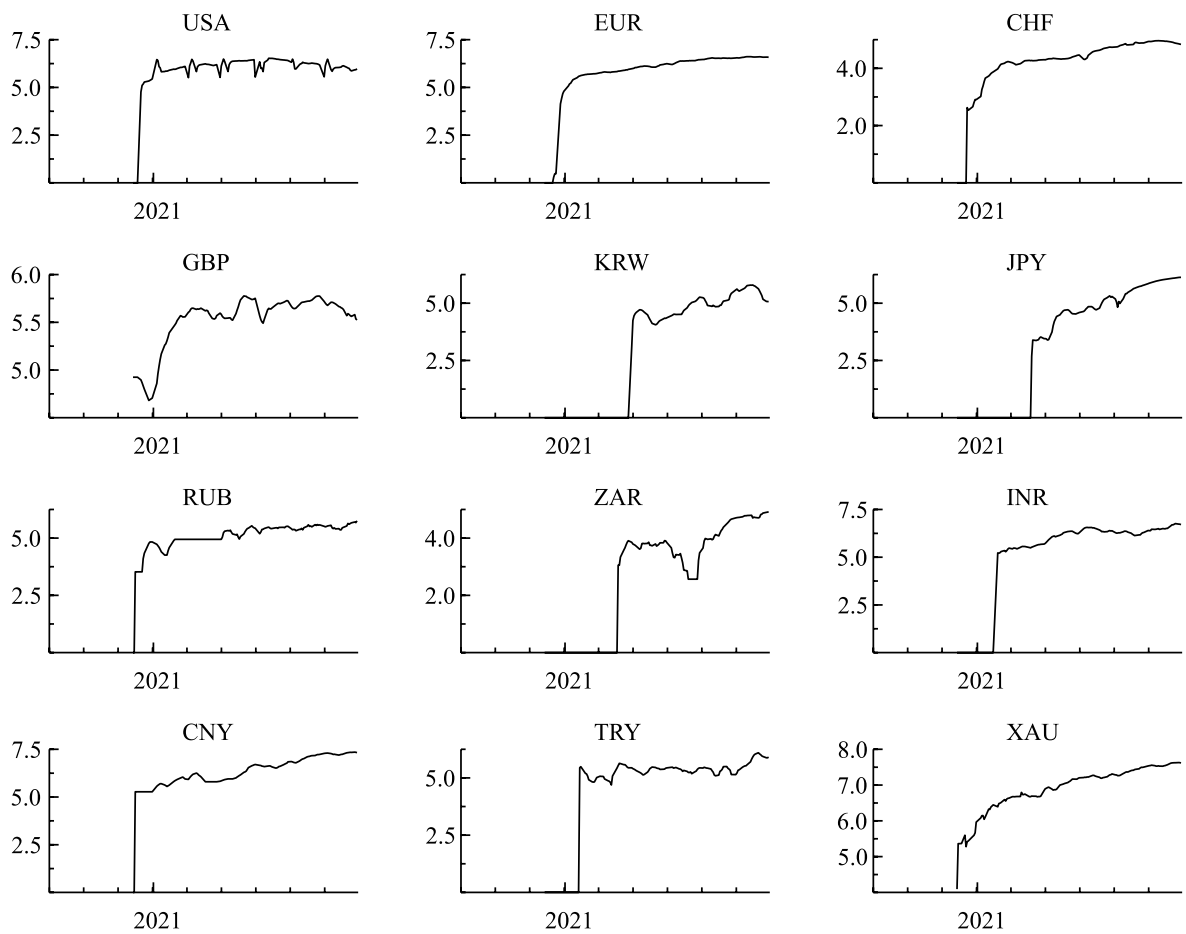

Fig. 3. Daily logarithmic number of COVID-19 vaccinations for the studied countries.

Source: Authors' calculations.

To use our data in heteroscedasticity models, we need to ensure stationarity. The Dickey-Fuller test results show that all variables are stationary at the first difference with a 5\% significance. Therefore, for heteroscedasticity modeling, we will use the first difference in our data (Table 3).

\subsection{DCC-GARCH model}

To assess the dynamic correlations between the forex exchange market and COVID-19 daily contaminations and vaccinations in the studied countries, we will use the DCC-GARCH model (Engle, 2002) due to its high flexibility and efficiency in modeling several variables with fewer elements to define. This model presents a matrix of dynamic conditional correlations over time. The estimate is made by computing conditional volatility for a multivariate GARCH process and then using standardized residues from this model to estimate dynamic correlations.

In our study, we will use the DCC-GARCH $(1,1)$ model commonly used in the economic literature and that we write as follows:

$$
H_{t}=\left(\begin{array}{ll}
h_{11, t} & h_{12, t} \\
h_{21, t} & h_{22, t}
\end{array}\right),
$$

where

$$
\begin{aligned}
& h_{11, t}=\alpha_{01}+\alpha_{11} \epsilon_{1, t-1}^{2}+\beta_{1,1} h_{11, t-1} \\
& h_{22, t}=\alpha_{02}+\alpha_{21} \epsilon_{2, t-1}^{2}+\beta_{2,1} h_{22, t-1} .
\end{aligned}
$$


Table 3

Results of the augmented Dickey-Fuller test for the studied times series.

\begin{tabular}{|c|c|c|c|c|c|c|c|}
\hline \multirow[t]{2}{*}{ Country } & & \multicolumn{2}{|c|}{$\begin{array}{l}\text { Currency pair against } \\
\text { USD }\end{array}$} & \multicolumn{2}{|c|}{$\begin{array}{l}\text { COVID-19 } \\
\text { contaminations }\end{array}$} & \multicolumn{2}{|c|}{$\begin{array}{l}\text { COVID-19 } \\
\text { vaccinations }\end{array}$} \\
\hline & & Level data & $1^{\text {st }}$ diff data & Level data & $1^{\text {st }}$ diff data & Level data & $1^{\text {st }}$ diff data \\
\hline \multirow[t]{2}{*}{ Worldwide } & Value & -0.8116 & -28.5107 & -1.5168 & -6.9958 & 1.2448 & -8.9526 \\
\hline & Prob & 0.8149 & 0.0000 & 0.5242 & 0.0000 & 0.9983 & 0.0000 \\
\hline \multicolumn{8}{|l|}{ Developed markets } \\
\hline \multirow[t]{2}{*}{ United States } & Value & -3.6663 & -15.944 & -1.4665 & -7.6304 & -4.3666 & -10.4533 \\
\hline & Prob & 0.2248 & 0.0000 & 0.5497 & 0.0000 & 0.8905 & 0.0000 \\
\hline \multirow[t]{2}{*}{ Europe } & Value & -1.7377 & -28.6164 & -1.4264 & -7.9515 & -0.2847 & -8.1150 \\
\hline & Prob & 0.4118 & 0.0000 & 0.5697 & 0.0000 & 0.9229 & 0.0000 \\
\hline \multirow[t]{2}{*}{ Switzerland } & Value & -1.4225 & -28.9692 & -3.3241 & -4.0082 & -1.3619 & -10.2707 \\
\hline & Prob & 0.5723 & 0.0000 & 0.2145 & 0.0015 & 0.5990 & 0.0000 \\
\hline \multirow[t]{2}{*}{ United Kingdom } & Value & -1.9346 & -27.6436 & -2.0831 & -3.8617 & -2.2162 & -8.4313 \\
\hline & Prob & 0.3164 & 0.0000 & 0.3287 & 0.0026 & 0.2016 & 0.0000 \\
\hline \multirow[t]{2}{*}{ South Korea } & Value & -2.2181 & -32.3367 & -2.1500 & -7.2774 & -2.2223 & -5.0414 \\
\hline & Prob & 0.2000 & 0.0000 & 0.2253 & 0.0000 & 0.1994 & 0.0000 \\
\hline \multirow[t]{2}{*}{ Japan } & Value & -2.9235 & -31.6859 & -2.7193 & -7.3499 & 2.5983 & -4.2579 \\
\hline & Prob & 0.6431 & 0.0000 & 0.1717 & 0.0000 & 0.9890 & 0.0000 \\
\hline \multicolumn{8}{|l|}{ Emerging markets } \\
\hline \multirow[t]{2}{*}{ Russia } & Value & -1.9112 & -31.7067 & -2.1272 & -3.7562 & -0.2040 & -11.2322 \\
\hline & Prob & 0.3272 & 0.0000 & 0.2342 & 0.0021 & 0.9340 & 0.0000 \\
\hline \multirow[t]{2}{*}{ South Africa } & Value & -1.7701 & -29.9507 & -2.6843 & -3.9718 & 2.3189 & -5.0150 \\
\hline & Prob & 0.3956 & 0.0000 & 0.1777 & 0.0018 & 0.9900 & 0.0000 \\
\hline \multirow[t]{2}{*}{ India } & Value & -2.3911 & -30.7487 & -1.4610 & -7.3837 & -0.2466 & -8.5771 \\
\hline & Prob & 0.2445 & 0.0000 & 0.5524 & 0.0000 & 0.9283 & 0.0000 \\
\hline \multirow[t]{2}{*}{ China } & Value & -0.8739 & -32.5299 & -1.1542 & -10.9680 & 0.8159 & -7.6706 \\
\hline & Prob & 0.7965 & 0.0000 & 0.3254 & 0.0000 & 0.9940 & 0.0000 \\
\hline \multirow[t]{2}{*}{ Turkey } & Value & -0.7584 & -15.0347 & -2.3359 & -7.4425 & -1.5976 & -7.0528 \\
\hline & Prob & 0.8295 & 0.0000 & 0.1612 & 0.0000 & 0.4810 & 0.0000 \\
\hline
\end{tabular}

Source: Authors' calculations.

\section{Results and discussion}

To efficiently analyze the results of the model, we will consider that depending on the value of the conditional correlation, the impacts of the daily COVID-19 contaminations and vaccinations are weak if $0 \leq \beta_{d c c}<0.5$, moderate if $0.5 \leq \beta_{d c c}<0.7$, strong if $0.7 \leq \beta_{d c c}<0.9$ and finally very strong if $0.9 \leq \beta_{d c c}$. The chronological evolution of dynamic correlations between the studied variables is plotted in Figs. 4 and 5.

The DCC GARCH model results in Table 4 exhibit a weak impact of daily COVID-19 contaminations on the UK forex market. These low dynamic correlations may result from the relatively slower outbreak in the country compared to other European countries and the limited lockdowns imposed by the liberal government in power. This finding contradicts those of Benzid and Chebbi (2020) and Arif et al. (2021) regarding the strong impact of COVID-19 contaminations on the USD/GBP exchange rate. This discrepancy may be related to the larger sample used in our study (515 days in the case of the UK) compared to those used by Benzid and Chebbi (2020) (101 days), and Arif et al. (2021) (334 days).

We should also note the moderate impact of daily COVID-19 contaminations on forex market volatility in South Korea. This result could be driven by 

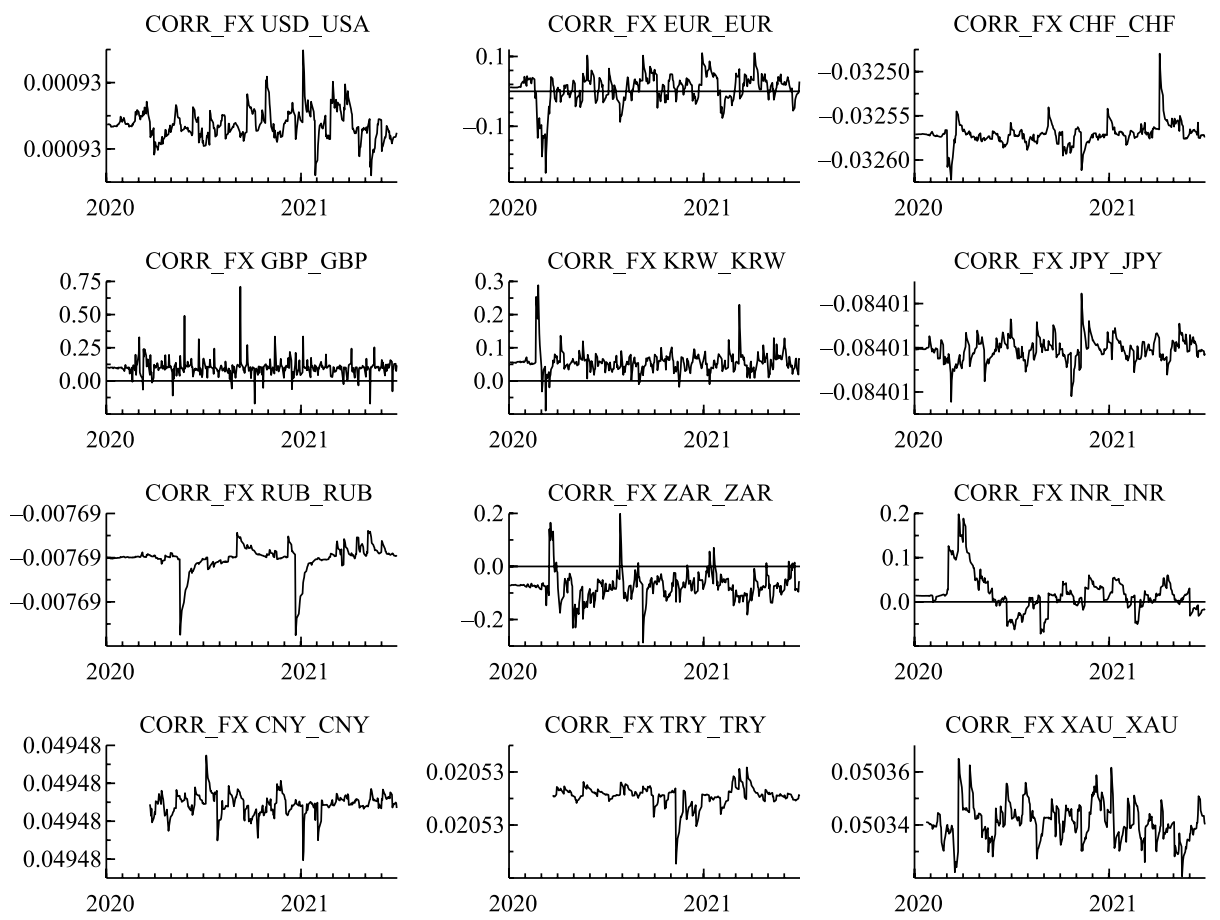

Fig. 4. Graph of conditional correlations between daily COVID-19 contaminations and exchange rates of the selected country sample.

Source: Authors' calculations.
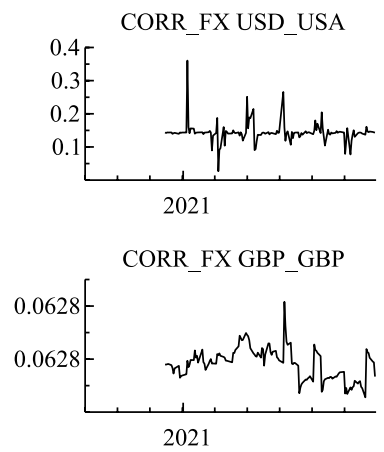

CORR FX RUB RUB

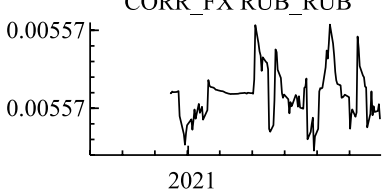

CORR_FXCNY_CNY

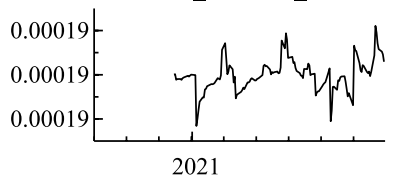

CORR_FX EUR_EUR

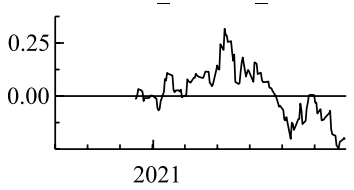

CORR_FX KRW_KRW

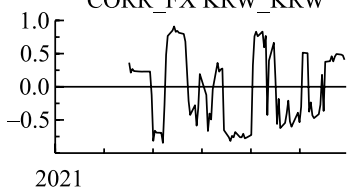

CORR FX ZAR ZAR

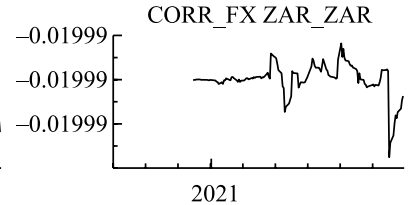

CORR_FX TRY_TRY

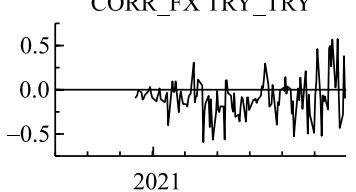

CORR_FX CHF_CHF

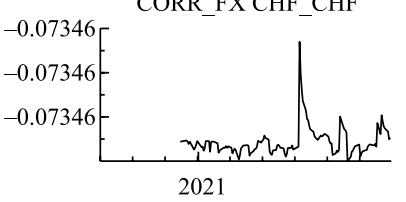

CORR_FX JPY_JPY

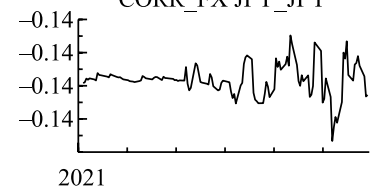

CORR FX INR INR

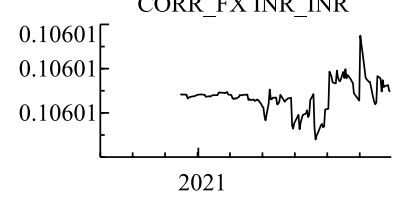

CORR_FX XAU_XAU

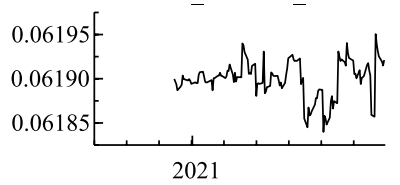

Fig. 5. Graph of conditional correlations between daily COVID-19 vaccinations and exchange rates of the selected country sample.

Source: Authors' calculations. 
Table 4

Results of DCC-GARCH Model between new COVID-19 Contaminations, daily COVID-19 vaccinations and exchange rates for the selected countries.

\begin{tabular}{|c|c|c|c|c|c|c|c|}
\hline \multirow[t]{2}{*}{ Country } & \multirow[t]{2}{*}{ Parity } & \multirow[t]{2}{*}{$\begin{array}{l}\text { Market } \\
\text { sentiment } \\
(\mathrm{MS}), \%\end{array}$} & & \multicolumn{2}{|c|}{$\begin{array}{l}\text { Conditional } \\
\text { correlations between } \\
\text { daily new COVID-19 } \\
\text { contaminations and } \\
\text { F.X. exchange rates } \\
\text { (FX-DC) }\end{array}$} & \multicolumn{2}{|c|}{$\begin{array}{l}\text { Conditional } \\
\text { correlations between } \\
\text { daily COVID-19 } \\
\text { vaccinations and } \\
\text { F.X. exchange rates } \\
\text { (FX-DV) }\end{array}$} \\
\hline & & & & $\beta_{d c c}$ & $\begin{array}{l}\text { Log- } \\
\text { likelihood }\end{array}$ & $\beta_{d c c}$ & $\begin{array}{l}\text { Log- } \\
\text { likelihood }\end{array}$ \\
\hline Worldwide & Gold price & -1.81 & $\begin{array}{l}\text { Value } \\
\text { Prob }\end{array}$ & $\begin{array}{l}0.8297 \\
0.0001\end{array}$ & 2583.69 & $\begin{array}{l}0.8147 \\
0.0168\end{array}$ & 1588.69 \\
\hline \multicolumn{8}{|l|}{ Developed Markets } \\
\hline United States & VIX Index & 6.35 & $\begin{array}{l}\text { Value } \\
\text { Prob }\end{array}$ & $\begin{array}{l}0.8280 \\
0.0000\end{array}$ & 2847.66 & $\begin{array}{l}0.8806 \\
0.0133\end{array}$ & 1346.21 \\
\hline Europe & USD/EUR & 13.11 & $\begin{array}{l}\text { Value } \\
\text { Prob }\end{array}$ & $\begin{array}{l}0.8266 \\
0.0000\end{array}$ & 1816.5 & $\begin{array}{l}0.9350 \\
0.0000\end{array}$ & 1122.11 \\
\hline Switzerland & $\mathrm{USD} / \mathrm{CHF}$ & -5.64 & $\begin{array}{l}\text { Value } \\
\text { Prob }\end{array}$ & $\begin{array}{l}0.8523 \\
0.0600\end{array}$ & 454.15 & $\begin{array}{l}0.8042 \\
0.0722\end{array}$ & 647.265 \\
\hline United Kingdom & USD/GBP & 141.39 & $\begin{array}{l}\text { Value } \\
\text { Prob }\end{array}$ & $\begin{array}{l}0.3624 \\
0.0038\end{array}$ & 1345.48 & $\begin{array}{l}0.8748 \\
0.2128\end{array}$ & 1038.27 \\
\hline South Korea & USD/KRW & 45.97 & $\begin{array}{l}\text { Value } \\
\text { Prob }\end{array}$ & $\begin{array}{l}0.6006 \\
0.0005\end{array}$ & 587.82 & $\begin{array}{l}0.8767 \\
0.0000\end{array}$ & 626.187 \\
\hline Japan & USD/JPY & 8.90 & $\begin{array}{l}\text { Value } \\
\text { Prob }\end{array}$ & $\begin{array}{l}0.7625 \\
0.0879\end{array}$ & 482.04 & $\begin{array}{l}0.8304 \\
0.0000\end{array}$ & 639.129 \\
\hline Emerging Markets & & & & & & & \\
\hline Russia & USD/RUB & -12.49 & $\begin{array}{l}\text { Value } \\
\text { Prob }\end{array}$ & $\begin{array}{l}0.9489 \\
0.0000\end{array}$ & 1263.63 & $\begin{array}{l}0.8304 \\
0.0000\end{array}$ & 1084.56 \\
\hline South Africa & USD/ZAR & 13.52 & $\begin{array}{l}\text { Value } \\
\text { Prob }\end{array}$ & $\begin{array}{l}0.7360 \\
0.0000\end{array}$ & 1164.25 & $\begin{array}{l}0.8355 \\
0.0894\end{array}$ & 692.871 \\
\hline India & USD/INR & -5.79 & $\begin{array}{l}\text { Value } \\
\text { Prob }\end{array}$ & $\begin{array}{l}0.9134 \\
0.0000\end{array}$ & 1555.07 & $\begin{array}{l}0.8605 \\
0.0023\end{array}$ & 1075.56 \\
\hline China & $\mathrm{USD} / \mathrm{CNY}$ & 1.19 & $\begin{array}{l}\text { Value } \\
\text { Prob }\end{array}$ & $\begin{array}{l}0.8303 \\
0.0001\end{array}$ & 517.42 & $\begin{array}{l}0.8402 \\
0.0829\end{array}$ & 1293.17 \\
\hline Turkey & USD/TRY & 5.05 & $\begin{array}{l}\text { Value } \\
\text { Prob }\end{array}$ & $\begin{array}{l}0.8122 \\
0.0101\end{array}$ & 1258.27 & $\begin{array}{l}0.8532 \\
0.0221\end{array}$ & 1131.84 \\
\hline
\end{tabular}

Source: Authors' calculations.

the successful monitoring conducted by Korean authorities since the first wave of COVID-19 contaminations. They have deployed considerable efforts, such as introducing mobile technology to track and trace the infected population, and the systematic testing of individuals further to various containment measures implemented earlier. Other factors may have also contributed to this result, as listed by Hoshikawa and Yoshimi (2021), such as the significant monetary and fiscal measures implemented by the Bank of Korea to support the economy, the depth of liquidity, and maturity of the Korean financial markets. The authors also point out the local populations' strong commitment to comply with protection and prevention measures compared with other Asian countries. Our finding corroborates and extends those of Hoshikawa and Yoshimi (2021) but contradicts those of Choi and Jung (2021) and Pyo (2021), who found a significant impact between COVID-19 contaminations and the Korean Stock Market. This contradiction may result from the speculation movements that prevailed on stock markets worldwide through 
the pandemic due to the loose monetary policies implemented by central banks and the democratization of trading platforms among non-specialist populations.

Another finding is the strong impact of the daily COVID-19 contaminations on forex exchange market volatility for most countries listed in the study regardless of their degree of development, namely the United States, Europe, Switzerland, Japan, South Africa, China and Turkey. All those countries (including those forming the Europe proxy) have open economies with heavy reliance on global supply chains. Therefore, as the pandemic evolved and authorities took strict sanitary measures (lockdowns, travel bans, capacity reduction), their domestic forex market became more responsive to COVID-19 data, mainly the daily COVID-19 contaminations. Furthermore, investors seeking safe haven assets triggered significant pressure on gold, U.S. dollars and the Swiss franc, especially when COVID-19 contaminations soared. These results corroborate those of Ozturk and Cavdar (2021) regarding the impact of COVID-19 contaminations worldwide and Turkish financial markets and Benzid and Chebbi (2020) for the case of USD/ EUR and USD/CNY currencies. These findings align with those of Sansa (2020) for the U.S. and Chinese financial markets.

We also observe a powerful impact of Daily COVID-19 contaminations in the cases of Russia and India, as shown in Table 4. These very high correlations may be the outcome of the significant exposure of both economies to commodities or exports services, heavily affected by the COVID-19 pandemic. Another likely factor could be the market participants' belief at the start of a prolonged bear cycle, the uncertainty about the pandemic evolution pathway, and its impact on the country's critical industrial and services sectors. Furthermore, on the macroeconomic front, both countries have adopted similar actions to alleviate the heavy socio-economic toll of the pandemic crisis through monetary policy. These policies included reducing key interest rates, relaxing macro-prudential banking rules, and easing inflow controls. The central banks pursuing managed float regimes intervened massively to support their currencies' external value, triggering large swings in forex volatilities.

Regarding the impact of COVID-19 vaccinations on the forex market, the results listed in Table 4 exhibit strong correlations for all the studied countries, especially in Europe, where the dynamic correlations are very high. This finding confirms previous conclusions regarding the strong impact of the COVID-19 vaccine's development on most developed and emerging markets (Vierlboeck and Nilchiani, 2021; Hartono, 2021; Kucher et al., 2021; Chan et al., 2021). Our results also corroborate the findings of the few existing articles regarding the study of the COVID-19 vaccination campaign on financial markets. Using different methodology and samples, the work of Khalfaoui et al. (2021) yields a similar conclusion for the U.S. financial market and Rouatbi et al. (2021) for the case of a larger sample of countries with various market degrees of maturity.

The next step in our study is to assess market sentiment in the studied countries. To do so, we will create a metric that we name "Market sentiment" (MS). This variable will determine what has a greater impact on the domestic forex market, COVID-19 contaminations or vaccinations data. We will define a pessimistic market sentiment when the daily COVID-19 contaminations impact the market more, exhibiting the prevailing fear factor among market actors in this country. On the other hand, we will define an optimistic market sentiment 
when the daily COVID-19 vaccinations impact the market more, which shows the market actors in this country are looking forward to the economy's recovery and that vaccination is the primary tool to get back to some "normalcy." We can synthesize the variable definition as follows:

$$
\left\{\begin{array}{l}
M S=\frac{\beta_{d c c}(F X-D V)-\beta_{d c c}(F X-D C)}{\beta_{d c c}(F X-D C)} \\
\text { if } M S<0 \Rightarrow \text { Pessimistic market sentiment } \\
\text { if } M S=0 \Rightarrow \text { Neutral market sentiment } \\
\text { if } M S>0 \Rightarrow \text { Optimistic market sentiment }
\end{array}\right.
$$

The results listed in Table 4 show that most developed countries have optimistic sentiment prevailing in their domestic market, except for Switzerland. This exception may be linked to the status of the Swiss franc as a safe haven asset during turbulent times. Therefore, it is more sensitive to data related to the COVID-19 contamination as market participants worldwide still fear the consequences of likely painful lockdowns in the future should the coronavirus spread out of control.

For the emerging markets, we observe mixed results, with South Africa, China and Turkey exhibiting an optimistic market sentiment while India and Russia exhibit a notable pessimistic mood. This contrast can be attributed to the disproportionate number of contaminations in both countries compared to the fully vaccinated population. As of June 30, 2021, India already had 30.4 million contaminations and only 57.7 million fully vaccinated individuals, representing only $4.2 \%$ of the total population. Russia had 5.4 million contaminations, and 17.3 million fully vaccinated individuals, representing $12 \%$ of the population. On the same date, the U.S. had $48 \%$ of its citizens fully vaccinated, the UK had $49 \%$, and Turkey had $18 \%$.

\section{Concluding remarks}

This article provided an updated analysis of the impact of COVID-19 daily contaminations and vaccinations on the financial markets by incorporating the third wave observed in 2021 . We adopted a synthetic approach based on many articles in the literature with remarkable differences regarding the sample size and methodology.

Our significant findings are that COVID-19 contaminations continued to affect economies strongly on different levels (except for the UK and South Korea), with an even more substantial impact in the cases of Russia and India. We also found that COVID-19 vaccinations greatly influenced all the studied countries, especially those forming the Euro bloc. Finally, our results showed that an optimistic market sentiment prevailed among our sample concerning the evolution of the pandemic and its impact on the financial market, except for Switzerland, Russia and India.

This study is one of the first to incorporate data from the heavy third wave characterized by the delta variant, making our results significant for market actors and policymakers worldwide. Further studies could focus on the micro-level to shed light on the atypical financial market behavior exhibited in our research in the cases of the UK, Russia and India. 


\section{References}

Adenomon, M. O., Maijamaa, B., \& John, D. O. (2020). On the effects of COVID-19 outbreak on the Nigerian stock exchange performance: Evidence from GARCH Models. Preprints, 2020040444. https://doi.org/10.20944/preprints202004.0444.v1

Arif, A., Saeed, A., \& Farooq, U. (2021). The behaviour of forex market during the first and second wave of COVID-19: A wavelet analysis. Applied Economics Letters. https://doi.org/10.1080/ 13504851.2021 .1962508

Baker, S. R., Farrokhnia, R. A., Meyer, S., Pagel, M., \& Yannelis, C. (2020). How does household spending respond to an epidemic? Consumption during the 2020 COVID-19 Pandemic. Review of Asset Pricing Studies, 10(4), 834-862. https://doi.org/10.1093/rapstu/raaa009

Benzid, L., \& Chebbi, K. (2020). The impact of COVID-19 on exchange rate volatility: Evidence through GARCH model. Available at SSRN: https://doi.org/10.2139/ssrn.3612141

Chan, K. F., Chen, Z., Wen, Y., \& Xu, T. (2021). COVID-19 vaccines and global stock markets. Available at SSRN: https://doi.org/10.2139/ssrn.3785533

Choi, C., and Jung, H. (2021). COVID-19's impacts on the Korean stock market. Applied Economics Letters. https://doi.org/10.1080/13504851.2021.1904099

Engle, R. (2002). Dynamic conditional correlation. Journal of Business and Economic Statistics, 20(3), 339-350. https://doi.org/10.1198/073500102288618487

Feng, G.-F., Yang, H.-C., Gong, Q., \& Chang, C.-P. (2021). What is the exchange rate volatility response to COVID-19 and government interventions? Economic Analysis and Policy, 69, 705-719. https://doi.org/10.1016/j.eap.2021.01.018

Gherghina, Ș. C., Armeanu, D. Ș., \& Joldeș, C. C. (2020). Stock market reactions to COVID-19 pandemic outbreak: Quantitative evidence from ARDL bounds tests and Granger causality analysis. International Journal of Environmental Research and Public Health, 17(18), 6729. https://doi.org/10.3390/ijerph17186729

Gherghina, S. C., Armeanu, D. S., \& Joldes, C. C. (2021). COVID-19 pandemic and Romanian stock market volatility: A GARCH approach. Journal of Risk and Financial Management, 14(8), 341. https://doi.org/10.3390/jrfm14080341

Guindy, M. A. (2021). Fear and hope in financial social networks: Evidence from COVID-19. Finance Research Letters. https://doi.org/10.1016/j.frl.2021.102271

Hai Le, T., Xuan Do, H., Nguyen, D. K., \& Sensoy, A. (2020). Covid-19 pandemic and taildependency networks of financial assets. Finance Research Letters, 38, 101800. https:// doi.org/10.1016/j.frl.2020.101800

Hartono, H. (2021). Covid-19 vaccine: Global stock market "game changer". Journal of Asian Multicultural Research for Economy and Management Study, 2(2), 8-17. https://doi.org/ 10.47616/jamrems.v2i2.102

Hofmann, B., Shim, I., \& Shin, H. S. (2021). Emerging market economy exchange rates and local currency bond markets amid the COVID-19 pandemic. Available at SSRN: https:// doi.org/10.2139/ssrn.3761875

Hoshikawa, T., \& Yoshimi, T. (2021). The effect of the COVID-19 pandemic on South Korea's stock market and exchange rate. Developing Economies, 59(2), 206-222. https://doi.org/ $10.1111 /$ deve. 12276

Iyke, B. N. (2020). The disease outbreak channel of exchange rate return predictability: Evidence from COVID-19. Emerging Markets Finance and Trade, 56(10), 2277-2297. https://doi.org/ 10.1080/1540496X.2020.1784718

Kartal, M. T., Depren, S. K., \& Depren, Ö. (2021). How main stock exchange indices react to COVID-19 pandemic: Daily evidence from East Asian countries. Global Economic Review, 50(1), 54-71. https://doi.org/10.1080/1226508X.2020.1869055

Khalfaoui, R., Nammouri, H., Labidi, O., \& Jabeur, S. B. (2021). Is the COVID-19 vaccine effective on the US financial market? Public Health, 198, 177-179. https://doi.org/10.1016/ j.puhe.2021.07.026

Kucher, O., Kurov, A., \& Wolfe, M. (2021). A shot in the arm: The effect of COVID-19 vaccine news on financial and commodity markets. Available at SSRN: https://doi.org/10.2139/ssrn.3852364

Makovský, P. (2014). Modern approaches to efficient market hypothesis of FOREX - The Central European case. Procedia Economics and Finance, 14, 397-406. https://doi.org/10.1016/ S2212-5671(14)00728-X 
Narayan, P. K. (2020). Has COVID-19 changed exchange rate resistance to shocks?. Asian Economics Letters, 1(1). https://doi.org/10.46557/001c.17389

Ngo, V. M., \& Nguyen, H. H. (2021). Are fear and hope of the COVID-19 pandemic responsible for the V-shaped behaviour of global financial markets? A text-mining approach. Applied Economics Letters. https://doi.org/10.1080/13504851.2021.1904105

Ozturk, M. B., \& Cavdar, S. C. (2021). The contagion of COVID-19 pandemic on the volatilities of international crude oil prices, gold, exchange rates and Bitcoin. Journal of Asian Finance, Economics and Business, 8(3), 171-179. https://doi.org/10.13106/JAFEB.2021.VOL8.NO3.0171

Pyo, D.-J. (2021). The COVID-19 and Stock Return Volatility: Evidence from South Korea. East Asian Economic Review, 25(2), 205-230. https://doi.org/10.11644/KIEP.EAER.2021.25.2.396

Rouatbi, W., Demir, E., Kizys, R., \& Zaremba, A. (2021). Immunizing markets against the pandemic: COVID-19 vaccinations and stock volatility around the world. International Review of Financial Analysis, 77, 101819. https://doi.org/10.1016/j.irfa.2021.101819

Salisu, A. A., Vo, X. V., \& Lawal, A. (2020). Hedging oil price risk with gold during COVID-19 pandemic. Resources Policy, 70, 101897. https://doi.org/10.1016/j.resourpol.2020.101897

Salisu, A., \& Akanni, L. (2020). Constructing a global fear index for the COVID-19 pandemic. Emerging Markets Finance and Trade, 56(10), 2310-2331. https://doi.org/10.1080/154049 6X.2020.1785424

Sansa, N. A. (2020). The impact of the COVID-19 on the financial markets: Evidence from China and USA. Electronic Research Journal of Social Sciences and Humanities, 2(2). https:// doi.org/10.2139/ssrn.3567901

Selmi, R., \& Bouoiyour, J. (2020). Global market's diagnosis on coronavirus: A tug of war between hope and fear. Available at HAL archives: https://hal.archives-ouvertes.fr/hal-02514428/

Shaikh, I., \& Huynh, T. L. (2021). Does disease outbreak news impact equity, commodity and foreign exchange market? Investors' fear of the pandemic COVID-19. Journal of Economic Studies. https://doi.org/10.1108/JES-10-2020-0503

Shmilovici, A., Kahiri, Y., Ben-Gal, I., \& Hauser, S. (2008). Measuring the efficiency of the intraday forex market with a universal data compression algorithm. Computational Economics, 33, 131-154. https://doi.org/10.1007/s10614-008-9153-3

Topcu, M., \& Gulal, O. S. (2020). The impact of COVID-19 on emerging stock markets. Finance Research Letters, 36, 101691. https://doi.org/10.1016/j.frl.2020.101691

Tunç, H. (2004). International trade, money and finance. Istanbul: Alfa Yayınları.

Vierlboeck, M., \& Nilchiani, R. R. (2021). Effects of COVID-19 vaccine developments and rollout on the capital market-A case study. Available at arXiv.org: https://arxiv.org/abs/ $2105.12267 \mathrm{v} 1$

Yiu, M. S., \& Tsang, A. (2021). Impact of COVID-19 on ASEAN5 stock markets. Journal of the Asia Pacific Economy. https://doi.org/10.1080/13547860.2021.1947550

Zhanga, D., Hua, M., \& Ji, Q. (2020). Financial markets under the global pandemic of COVID-19. Finance Research Letters, 36, 101528. https://doi.org/10.1016/j.frl.2020.101528 